\title{
Comparison of Morphological Characteristics of the Subaxial Cervical Spine between Athetoid Cerebral Palsy and Normal Control
}

\author{
Jun Young Kim, M.D., Jae Yeol Kwon, M.D., ${ }^{2}$ Moon Seok Kim, M.D., ${ }^{2}$ Jeong Jae Lee, M.D., ${ }^{2}$ Il Sup Kim, M.D., Ph.D., ${ }^{2}$ \\ Jae Taek Hong, M.D., Ph.D. ${ }^{2}$ \\ Department of Neurosurgery, Wiltse Memorial Hospital, Suwon, Korea \\ Department of Neurosurgery, ${ }^{2}$ St. Vincent's Hospital, College of Medicine, The Catholic University of Korea, Suwon, Korea
}

Objective : To compare the morphometry of subaxial cervical spine between cerebral palsy (CP) and normal control.

Methods : We retrospectively analyzed 72 patients with $\mathrm{CP}$, as well as 72 patients from normal population. The two groups were matched for age, sex, and body mass index. Pedicle, lateral mass (LM), and vertebral foramen were evaluated using computed tomography (CT) imaging. Pedicle diameter, LM height, thickness, width and vertebral foramen asymmetry (VFA) were measured and compared between the two groups. Cervical dynamic motion, disc and facet joint degeneration were investigated. Additionally, we compared the morphology of LM between convex side and concave side with cervical scoliotic CP patients.

Results : LM height was smaller in CP group. LM thickness and width were larger in CP group at mid-cervical level. In 40 CP patients with cervical scoliosis, there were no height and width differences between convex and concave side. Pedicle outer diameter was not statistically different between two groups. Pedicle inner diameter was significantly smaller in CP group. Pedicle sclerosis was more frequent in CP patients. VFA was larger in CP group at C3, C4, and C5. Disc/facet degeneration grade was higher in the CP group. Cervical motion of $\mathrm{CP}$ group was smaller than those of the control group.

Conclusion : LM morphology of CP patients was different from normal population. Sclerotic pedicles and vertebral foramen asymmetry were more commonly identified in CP patients. CP patients were more likely to demonstrate progressive disc/facet degeneration. This data may provide useful information on cervical posterior instrumentation in CP patients.

Key Words : Cerebral palsy · Cervical spine $\cdot$ Morphology $\cdot$ Motion.

\section{INTRODUCTION}

Athetoid cerebral palsy $(\mathrm{CP})$ is a static encephalopathy caused by neonatal hypoxia occurring during the perinatal or postna- tal phases of development. Early onset of extensive spondylosis of the cervical spine, deformity and instability due to sustained abnormal muscular tonicity, or excessive movement of the neck are found in patients with athetoid type of cerebral palsy ${ }^{2,6,10)}$.

- Received : March 31, 2017 • Revised : July 23, 2017 •Accepted : August 13, 2017

- Address for reprints : Jae Taek Hong, M.D., Ph.D.

Department of Neurosurgery, St. Vincent's Hospital, College of Medicine, The Catholic University of Korea, 93 Jungbu-daero, Paldal-gu, Suwon 16247, Korea Tel : +82-31-249-7196, Fax : +82-31-249-5208, E-mail : jatagi15@gmail.com

This is an Open Access article distributed under the terms of the Creative Commons Attribution Non-Commercial License (http://creativecommons.org/licenses/by-nc/4.0) which permits unrestricted non-commercial use, distribution, and reproduction in any medium, provided the original work is properly cited. 
And many of them progressively more disabled and surgical treatment is usually required.

Several surgical procedures have been described; in the earlier era of the operation for cervical spondylotic myelopathy associated with cerebral palsy, decompressive laminectomy was frequently performed, but it caused spinal instability and consequent recurrence of symptoms ${ }^{2,12)}$. For these reasons, cervical instrumentation and fusion are essential.

Clinically, there are many characteristic features of patients with athetoid cerebral palsy compared to normal population including dystonic athetoid neck movements ${ }^{2,4,6)}$. Morphological characteristics of cervical spine in CP patients are different from those of normal patients. As a result, a better understanding of the morphological characteristics of the cervical spine in patients with CP would be important to surgeons performing safer and more accurate instrumentation. The aim of this study was to compare the morphometric subaxial cervical spine between patients with athetoid cerebral palsy and normal population.

\section{MATERIALS AND METHODS}

After Institutional Review Board approval, we retrospectively reviewed radiologic study of 72 patients with $\mathrm{CP}$, as well as 72 normal controls without cerebral palsy. The two groups underwent multiplanar computed tomography (CT) and an Xray of the cervical vertebrae from 2006 to 2014 . We compared the morphological characteristics of subaxial cervical spine between two groups.CP group included 32 males and $40 \mathrm{fe}-$ males. Their mean age was 42.6 years (range, $22-74$ years) at the time of cervical radiological evaluation. Mean body mass index (BMI) was 21.6 (range, 17.8-24.2). Among them, 21 patients had received instrumentation and fusion surgery for cervical compressive myelopathy due to subaxial lesion. For these patients, we reviewed the preoperative radiologic study. The control group included 32 males and 40 females who checked CT scan due to the mild trauma without any history of cervical spine disease. Each patient in the control group was matched to the age and BMI of a CP patient. Mean age in the control group was 44.2 years (range, $24-76$ years) and mean BMI was 21.5 (range, 17.5-23.8).

Both groups underwent standardized axial bone-window CT scanning and a plain X-ray of cervical spine. All CT scans were performed on a Siemens 64-slice CT scanner with 3-mm axial image thickness (Siemens Medical Solutions, Erlangen, Germany). Sagittal and coronal reconstructions were obtained using 1.25-mm thickness slices. CT films were scanned at a resolution of $512 \times 512$ pixels, a field of view of $180 \mathrm{~mm}$, and $\mathrm{CT}$ interactive software was used to edit the images. Linear and angular measurements were made using m-view 5.4 software (Marosis Technologies Inc., Seoul, Korea).

\section{Lateral mass}

We performed a morphometric analysis of the lateral masses from C3-C7 by taking measurements of anterior height (LMAH), posterior height (LMPH), thickness (LMT), width (LMW) on a true axial, and sagittal CT slice that passed by the center of the lateral mass. LMAH was the distance between the two adjacent joints on the anterior aspect of the lateral mass and LMPH was the distance between the two adjacent joints on the posterior aspect of the lateral mass. LMT was the distance between the dorsal and ventral cortices of the center of the lateral mass and LMW had the largest width of lateral mass on axial CT image (Fig. 1). We compared the morphology of subaxial lateral masses (LMAH, LMPH, LMT, and LMW) between convex side lateral mass and concave side lateral mass with cervical scoliotic CP patients. In 30 patients, cervical coronal scoliosis was confirmed. Cervical coronal scoliosis was defined as coronal Cobb's angle greater than $10^{\circ}$ on an anterior-posterior plain cervical X-ray.

\section{Pedicle and transverse foramen}

On the surfaces that passed the axes of bilateral pedicles, the pedicle outer diameter (POD), and inner diameter (PID) of both pedicles in C3 to C7 were measured. POD was outer cortical diameter and PID was inner cancellous diameter (Fig. 1). Vertebral foramen asymmetry (VFA) was evaluated in C3 to C6 by measuring the difference between the left and right distance from the midline (Fig. 1). C7 was excluded because of absence or hypoplasia of vertebral foramen.

\section{Degeneration of disc and facet joint}

Degeneration of cervical discs from C3 to C7 was graded on lateral cervical radiographs. The grading of cervical disc degeneration was based on the grading system previously described in Hilibrand et al. ${ }^{7)}$ The degree of degeneration was graded into three categories : grade I, normal; grade II, narrow- 

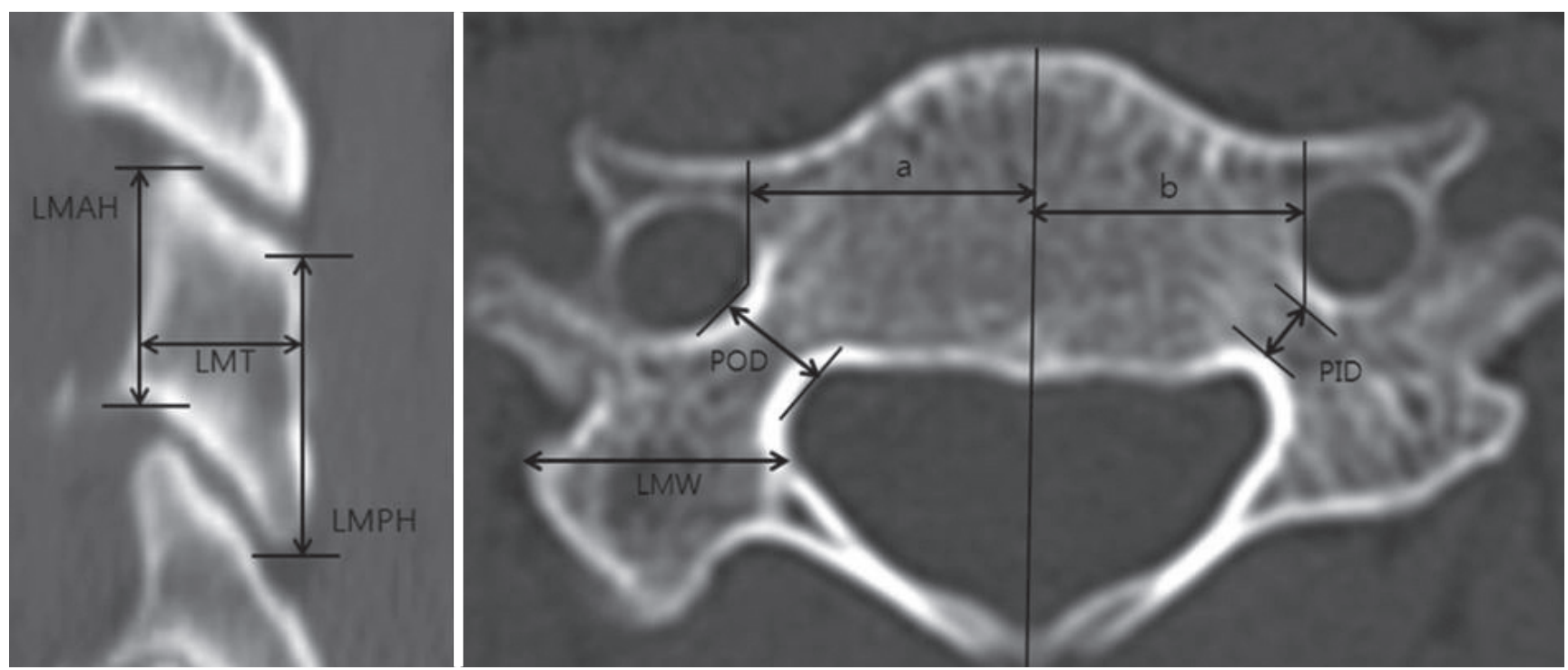

Fig. 1. A schematic diagram of the lateral mass, pedicle and vertebral foramen asymmetry parameters measured on computed tomography scans. LMAH: lateral mass anterior height, LMT : lateral mass thickness, LMPH : lateral mass posterior height, $a$ : distance from the midline to right vertebral foramen, $b$ : distance from the midline to left vertebral foramen, POD : pedicle outer diameter, LMW : lateral mass width, PID : pedicle inner diameter.

ing of disc space and no posterior osteophytes; and grade III, less than $50 \%$ of normal disc space height and posterior osteophytes are present. The degree of cervical facet degeneration was bilaterally determined on CT from C3 to C7. The grading of cervical facet degeneration was based on the grading system previously described in Park et al. ${ }^{19)}$. The degree of degeneration was graded into four categories : grade I, normal; grade II, degenerative changes including joint space narrowing, cyst formation, small osteophytes without joint hypertrophy seen on axial or sagittal images; grade III, joint hypertrophy secondary to large osteophytes without fusion on axial or coronal images; and grade IV, bony fusion of the joint seen on sagittal images.

\section{Cervical spine motion}

We reviewed dynamic lateral plain X-rays for the comparison of cervical dynamic motion range between the two groups by measuring occipital-C2 angle (O-C2A), $\mathrm{C} 2-\mathrm{C} 7$ angle (C2$7 \mathrm{~A})$, and occipital-C7 angle (O-C7A). The $\mathrm{O}-\mathrm{C} 2 \mathrm{~A}$ indicates the angle between McGregor's line and the inferior vertebral endplate line of $\mathrm{C}_{2}^{20)}$. The $\mathrm{C} 2-\mathrm{C} 7 \mathrm{~A}$ indicates the angle between the inferior endplates of the $\mathrm{C} 2$ and $\mathrm{C} 7$ vertebral bodies. The O-C7A indicates the angle between McGregor's line and the inferior vertebral endplate line of $\mathrm{C} 7$. The differences in the O-C2A (dOC2A), C2-C7A (dC27A), O-C7A (dOC7A), i.e., the differences between the values in the flexion and the value in the extension position, were calculated for both groups (Fig. 2).

\section{Statistical analysis}

All analyses performed with the IBM SPSS Statistics software program version 18 (SPSS Inc., Somers, NY, USA). For the comparisons of the parameters between the groups, paired t-test for normally distributed continuous variables and Wilcoxon signed-rank test for non-normally distributed continuous variables was used and Fisher exact were used for categorical data. For all statistical tests, $p<0.05$ was considered to be significant.

\section{RESULTS}

A total of 144 lateral masses were compared between CP group and the control group. LMAH in CP group was ranged from 7.8 to $15.8 \mathrm{~mm}$ and it was found to be smaller than that in the control group on all cervical levels ( $p<0.01$, Fig. 3 ). LMPH in CP group ranged from 7.1 to $15.7 \mathrm{~mm}$ and was found to be smaller than that of the control group at C3, C4, and C5 $(p<0.01)$. LMT in CP group was ranged from 5.2 to $18.5 \mathrm{~mm}$ and was found to be larger than that of the control group at $\mathrm{C} 3$ and $\mathrm{C} 4$ ( $p<0.01$ and $p=0.02$, respectively). At C5, C6, and C7, there was 


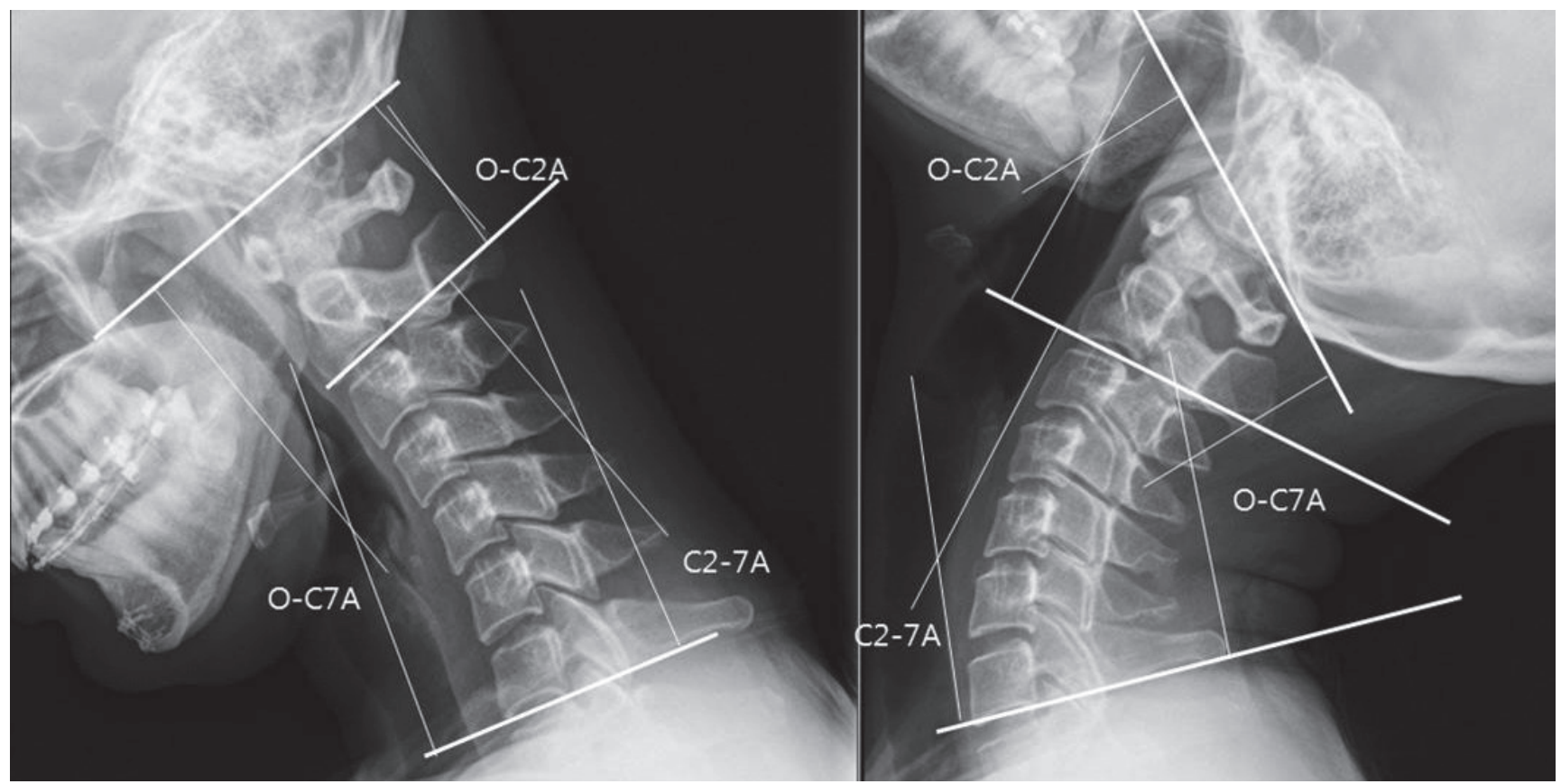

Fig. 2. Dynamic lateral plain X-rays for cervical dynamic motion range. The O-C2A represents the angle between McGregor's line and the inferior endplate of $\mathrm{C}$. The C2-7A represents the angle between the inferior endplates of C2 and C7. The O-C7A represents the angle between McGregor's line and the inferior endplate of $\mathrm{C} 7$.

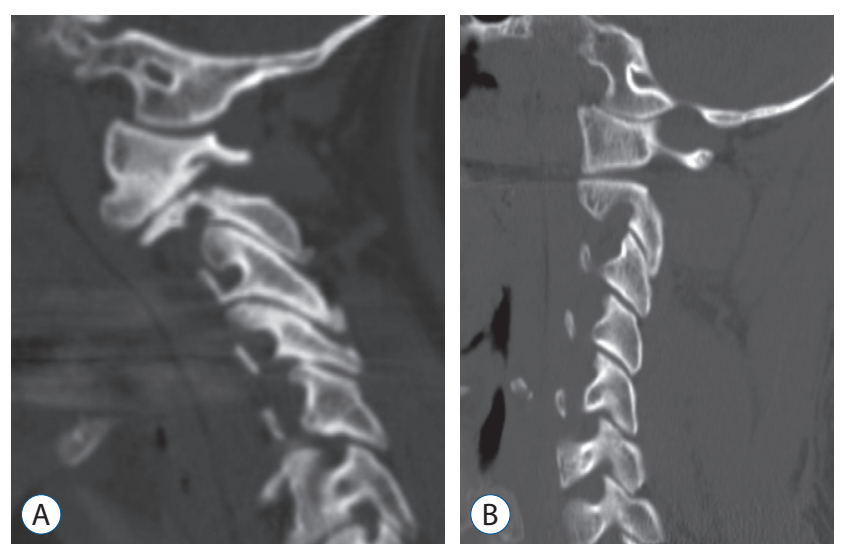

Fig. 3. Parasagittal computed tomography reconstruction images show lateral mass height of cerebral palsy group $(\mathrm{A})$ is smaller than that in the control group (B) on all cervical levels.

no difference between two groups in terms of LMT. Also, LMW in $\mathrm{CP}$ group was ranged from 9.0 to $18.5 \mathrm{~mm}$ and was found to be larger than that of the control group on all levels $(p<0.05)$ except for C7 (Table 1). For 40 patients in CP group with cervical scoliosis, there were no significant differences of LMAH, LMPH, LMT, LMW between convex side lateral mass and concave side lateral mass $(p>0.05)$.

POD in CP group ranged from 2.7 to $8.5 \mathrm{~mm}$ and no significant differences were observed with POS of the control group on all cervical levels. PID in CP group ranged from 0.3 to 6.3 $\mathrm{mm}$ and was found to be smaller than that of the control group on all cervical levels $(p<0.05$, Table 2$)$. Pedicle sclerosis is identified in the 12 patients of the CP group. However there was only one pedicle sclerosis in normal control group (16.7\% vs. $1.4 \%, p<0.01$, Fig. 4). VFA in CP group ranged from 0 (symmetric vertebral foramen from midline) to $4.4 \mathrm{~mm}$ and was found to be larger than that of the control group at C3, C4, and C5 $(p<0.05)$. At C6, VFA had a tendency for increase compared to the control group ( $p=0.07$ ), but this difference was not statistically significant (Table 2).

When comparing cervical disc degeneration grade and facet degeneration grade, the patients in $\mathrm{CP}$ group were statistically more likely to demonstrate progressive disc degeneration than the patients in the control group $(p<0.01)$. Disc degeneration above grade II accounted for $95.3 \%$. Facet degeneration in CP group was statistically more progressed than in the control group $(p<0.01)$. Facet degeneration above grade II accounted for $89.4 \%$ (Table 3 ).

The mean value of dOC2A in CP group was $26.2^{\circ}$ in the range from $1.1^{\circ}$ to $65.2^{\circ}$; the mean value of $\mathrm{dC} 27 \mathrm{~A}$ in $\mathrm{CP}$ group was $47.8^{\circ}$ in the range from $1.8^{\circ}$ to $65.2^{\circ}$; both values were smaller than the corresponding values in the control group, 
Cervical Spine Morphology of Cerebral Palsy and Normal Control | Kim JY, et al.

Table 1. The measurement of lateral mass profiles in CP group and control group

\begin{tabular}{|c|c|c|c|c|c|}
\hline & C3 & C4 & C5 & C6 & C7 \\
\hline \multicolumn{6}{|c|}{ Anterior height (mm) } \\
\hline$C P$ & $11.3 \pm 1.8$ & $11.7 \pm 1.4$ & $10.8 \pm 1.2$ & $11.4 \pm 1.5$ & $12.6 \pm 1.6$ \\
\hline Control & $12.4 \pm 1.3$ & $12.7 \pm 1.5$ & $12.1 \pm 1.0$ & $12.3 \pm 1.0$ & $13.6 \pm 1.2$ \\
\hline$p$-value & 0.003 & 0.001 & 0.000 & 0.004 & 0.010 \\
\hline \multicolumn{6}{|c|}{ Posterior height (mm) } \\
\hline $\mathrm{CP}$ & $12.4 \pm 2.0$ & $11.5 \pm 1.6$ & $11.6 \pm 1.7$ & $12.2 \pm 2.0$ & $12.3 \pm 2.3$ \\
\hline Control & $14.2 \pm 2.1$ & $12.3 \pm 1.6$ & $12.9 \pm 1.2$ & $12.4 \pm 1.4$ & $12.4 \pm 2.0$ \\
\hline$p$-value & 0.001 & 0.020 & 0.000 & 0.067 & 0.946 \\
\hline \multicolumn{6}{|c|}{ Thickness (mm) } \\
\hline $\mathrm{CP}$ & $10.1 \pm 2.4$ & $11.7 \pm 2.9$ & $10.7 \pm 2.0$ & $10.1 \pm 2.0$ & $8.3 \pm 1.6$ \\
\hline Control & $9.2 \pm 1.1$ & $9.8 \pm 1.3$ & $10.2 \pm 1.6$ & $9.7 \pm 1.5$ & $9.2 \pm 2.5$ \\
\hline$p$-value & 0.048 & 0.001 & 0.251 & 0.337 & 0.055 \\
\hline \multicolumn{6}{|c|}{ Width (mm) } \\
\hline $\mathrm{CP}$ & $12.9 \pm 2.2$ & $12.8 \pm 2.1$ & $13.4 \pm 1.6$ & $13.1 \pm 1.7$ & $12.7 \pm 1.3$ \\
\hline Control & $12.0 \pm 1.1$ & $11.7 \pm 0.8$ & $12.2 \pm 1.2$ & $12.3 \pm 1.1$ & $12.4 \pm 1.2$ \\
\hline$p$-value & 0.044 & 0.003 & 0.000 & 0.012 & 0.269 \\
\hline
\end{tabular}

Values are presented as mean \pm standard deviation. Data from 72 subjects. Significant $p$-value $<0.05$. CP : cerebral palsy

Table 2. The measurement of pedicle profiles and vertebral foramen asymmetry in CP group and control group

\begin{tabular}{|c|c|c|c|c|c|}
\hline & C3 & C4 & $\mathrm{C5}$ & C6 & $\mathrm{C7}$ \\
\hline \multicolumn{6}{|c|}{ Outer diameter (mm) } \\
\hline$C P$ & $5.9 \pm 1.1$ & $5.5 \pm 1.0$ & $5.5 \pm 1.0$ & $5.7 \pm 0.8$ & $6.5 \pm 1.0$ \\
\hline Control & $5.3 \pm 0.8$ & $5.6 \pm 0.8$ & $5.8 \pm 0.9$ & $5.7 \pm 0.9$ & $6.6 \pm 0.8$ \\
\hline$p$-value & 0.044 & 0.325 & 0.356 & 0.819 & 0.755 \\
\hline \multicolumn{6}{|c|}{ Inner diameter (mm) } \\
\hline $\mathrm{CP}$ & $2.1 \pm 0.9$ & $2.0 \pm 0.7$ & $1.9 \pm 0.8$ & $1.9 \pm 0.8$ & $3.1 \pm 1.4$ \\
\hline Control & $2.9 \pm 0.7$ & $3.0 \pm 1.0$ & $3.1 \pm 1.0$ & $3.1 \pm 1.0$ & $4.1 \pm 0.9$ \\
\hline$p$-value & 0.003 & 0.001 & 0.000 & 0.000 & 0.019 \\
\hline \multicolumn{6}{|c|}{ Vertebral foramen asymmetry } \\
\hline $\mathrm{CP}$ & $1.3 \pm 0.8$ & $1.5 \pm 0.8$ & $1.2 \pm 1.1$ & $1.2 \pm 1.0$ & $1.1 \pm 1.1$ \\
\hline Control & $0.5 \pm 0.3$ & $0.7 \pm 0.5$ & $0.6 \pm 0.5$ & $0.7 \pm 0.5$ & $0.8 \pm 0.6$ \\
\hline$p$-value & 0.000 & 0.001 & 0.038 & 0.070 & 0.686 \\
\hline
\end{tabular}

Values are presented as mean \pm standard deviation. Significant $p$-value $<0.05$. Vertebral foramen asymmetry, the difference between the left and right distance from the midline to the vertebral foramen. CP : cerebral palsy

although the differences did not reach statistical significance. The mean value of dOC7A in CP group was $74.1^{\circ}$ in the range from $41.9^{\circ}$ to $109.8^{\circ}$ and was found to be significantly smaller than that of the control group ( $p=0.039$, Table 4 ).

\section{DISCUSSION}

Early onset of cervical degeneration due to sustained abnormal tonicity or movement of the neck was found in the patients with cerebral palsy. In surgery, several studies reported that decompression without fusion or laminoplasty is not recom- 


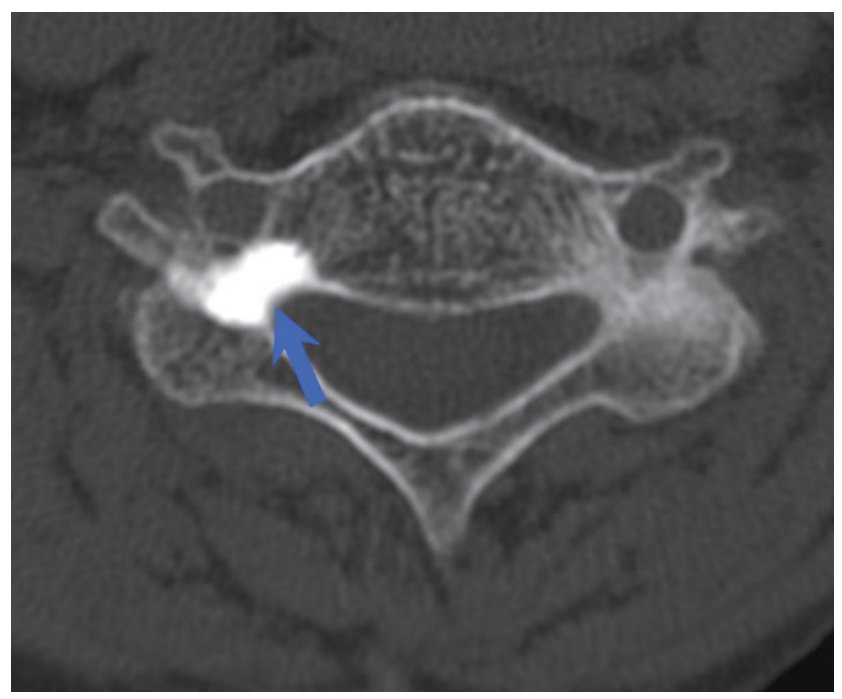

Fig. 4. Axial computed tomography image shows the osteosclerotic changes of the right pedicle (arrow).

mended because of repetitive cervical abnormal movement, adjacent segment instability, and progression of spondylo$\operatorname{sis}^{13,17,18,22)}$. Therefore, rigid instrumented fixation is required to obtain satisfactory outcome.

Since the advent of cervical lateral mass screw fixation by Roy-Camille et al. ${ }^{21)}$ in 1972, several techniques for lateral screw placement are available, including Roy-Camille, Louis, Magerl, Anderson techniques ${ }^{1,8,16}$. The anatomic structures at risk during lateral mass screwing of the cervical spine are the nerve roots, the vertebral arteries, and the adjacent lateral masses ${ }^{3}$. The lateral mass screw fixation is safer than the cervical pedicle screw fixation; however, if the lateral mass is small or if the lateral mass or facet joint has been fractured, the lateral mass screw fixation may entail the problem of screw loosening or avulsion ${ }^{9,14,16)}$. Furuya et al. ${ }^{4)}$ reported that subaxial pedicle instrumentation contribute to the achievement of relatively good surgical outcomes for CP patients. Several studies reported that abnormal neck motion of CP patients accelerates degenerative change of cervical spine ${ }^{9,22)}$. Harada et al. ${ }^{5)}$ reported that the cervical spine in patients with $\mathrm{CP}$ is characterized by vertebral body flattening and a narrow sagittal spinal canal diameter. Kato et al." reported that pedicle sclerosis, a wide transverse angle, and a lateral mass deformity were frequently observed in patients with CP. Our study described the morphological characteristics of subaxial cervical spine in patients with athetoid CP compared with age-, BMI-matched normal population for safe cervical instrumentation.
Table 3. Grade of disc degeneration and facet degeneration in CP group and control group

\begin{tabular}{lcc}
\hline & CP (\%) & Control (\%) \\
\hline Disc degeneration & & \\
Grade I & 4.7 & 43.5 \\
Grade II & 42.4 & 47.1 \\
Grade III & 52.9 & 9.4 \\
Facet degeneration & & \\
Grade I & 10.6 & 50.0 \\
Grade II & 40.0 & 43.7 \\
Grade III & 45.9 & 6.3 \\
Grade IV & 3.5 & 0 \\
\hline
\end{tabular}

CP : cerebral palsy

Table 4. Cervical dynamic motion in CP group and control group

\begin{tabular}{lccc}
\hline & dOC2A & dC27A & dOC7A \\
\hline CP & & & \\
Mean angle (degree) & 33.2 & 53.2 & 86.4 \\
Range (degree) & $13.5-76.2$ & $35.3-71.1$ & $57.4-144.3$ \\
Control & & & \\
Mean angle (degree) & 26.2 & 47.8 & 74.1 \\
Range (degree) & $1.1-65.2$ & $1.8-65.2$ & $41.9-109.8$ \\
-value & 0.215 & 0.396 & 0.039 \\
\hline
\end{tabular}

Significant $p$-value $<0.05$. CP : cerebral palsy, dOC2A : the differences between the values of occipital-C2 angle in the flexion and the value in the extension position, $\mathrm{dC} 27 \mathrm{~A}$ : the differences between the values of $\mathrm{C} 2-\mathrm{C} 7$ angle in the flexion and the value in the extension position, dOC7A : the differences between the values of occipital-C7 in the flexion and the value in the extension position

This study first described the morphological characteristics of lateral mass in patients with CP. Superior-inferior mean diameter (LMAH and LMPH) of CP group ranged from 10.8 to 12.6 and was smaller than that of the control group. These findings mean that lateral mass of CP patients is superior-inferiorly smaller and anterior-posteriorly, mediolaterally larger than that of normal population especially in the mid-cervical spine. So, selection of the entry point and sagittal angulation may be important to avoid facet joint violation during the lateral mass screw placement in the $\mathrm{CP}$ patient. Also, these data indicate that the greater stress is generated at the mid-cervical spine than the lower cervical spine in the $\mathrm{CP}$ patient. The sudden increase in size at $\mathrm{C} 6$ and $\mathrm{C} 7$ of the vertebral bodies and spinous processes in the human cervical spine may explain this finding because the shearing stress per area unit becomes big- 
ger as the vertebra decreases in size. Furthermore, there was no directional difference of lateral mass degeneration for $\mathrm{CP}$ patients of cervical scoliosis. This means, for CP patients, abnormal neck motion worsens cervical degeneration on both concave and convex sides. In this study, we found that the mean pedicle outer diameter in CP group was 5.5 to $6.6 \mathrm{~mm}$ and the outer diameter was not different from that of the control group except for C3. The mean outer diameter in the control group was 5.3 to $6.6 \mathrm{~mm}$ and it was similar to the outer diameter measured by CT in Kato et al. ${ }^{9}$. The mean inner diameter in the control group was 1.9 to $3.1 \mathrm{~mm}$ and the inner diameter was smaller than that of the control group on all subaxial cervical levels. Pedicle sclerosis was frequently observed in patients with $\mathrm{CP}$ as well. This finding suggests that the safety margin for pedicle screw fixation could be narrower in the CP group compared with the normal population. Two studies reported that the breach rate was higher in patients with $\mathrm{CP}$ because of loss of anatomical landmarks in a vertebra and the osteosclerotic changes of the pedicle ${ }^{14,15)}$. Therefore, cervical pedicle screw instrumentation could be dangerous especially for $\mathrm{CP}$ patients with massive spondylosis.

Regard to the vertebral foramen asymmetry of CP patients, in CP group, the mean difference value between the left and right distance from the midline was larger than $1 \mathrm{~mm}$, whereas it was smaller than $1 \mathrm{~mm}$ for the control group. Our results indicate that vertebral foramen of subaxial cervical spine of $\mathrm{CP}$ patients is more asymmetric than that of normal population. We suppose that vertebral foramen asymmetry is associated with massive degeneration of cervical spine of $\mathrm{CP}$ patients.

In this study, patients in CP group were more likely to demonstrate progressive disc, facet degeneration than patients in the control group. Harada et al. ${ }^{5)}$ reported that disc degeneration occurred earlier and progressed more rapidly in the patients with advanced disc degeneration in $51 \%$, i.e., eight times the frequency in normal subjects. In our study, severe disc degeneration above grade III was observed in $52.9 \%$ of cases in $\mathrm{CP}$ group, similarly to previous reports. We graded the degree of facet degeneration into four categories. Park et al. ${ }^{19)}$ reported that greater than grade III facet joint arthrosis was common in patients older than 60 years old and at $\mathrm{C} 2-\mathrm{C} 3, \mathrm{C} 3-\mathrm{C} 4$, and C4-C5. In our study, facet degeneration above grade III was observed in $49.4 \%$ of $\mathrm{CP}$ group. Facet degeneration occurred earlier and progressed more rapidly in the patients of CP. We suppose that disc and facet degeneration were aggravated by sustained muscular tonicity and excessive movement of the neck in CP patients.

$\mathrm{CP}$ patients show various involuntary movements of the neck, face, arms, and upper body. Previously, it was erroneously assumed that cervical motion range of CP patients was larger than normal population. By contrast, the results of the present study show that cervical neck motion range of $\mathrm{CP}$ group was smaller than that of the control group. Although not statistically significant, dOC2A and dC27A of CP group were smaller than those of the control group. However, dOC7A was significantly smaller than that of the control group. Phillips et al. ${ }^{20)}$ reported that, in the measurement of $\mathrm{C} 0-\mathrm{C} 2$ angle differences between flexion and extension Xray, the mean value of $\mathrm{C} 0-2$ angle differences in healthy patients was about $33^{\circ}$ and larger than that of $\mathrm{CP}$ group. Kim et al. ${ }^{11)}$ reported the measurement of $\mathrm{C} 2-\mathrm{C} 7$ angle differences between flexion and extension X-ray for 105 patients with symptomatic single or two-level cervical disc disease. The mean value of $\mathrm{C} 2-7$ angle differences in cervical disc patients was about $50^{\circ}$ and larger than that of $\mathrm{CP}$ group. We suppose that the decrease of cervical dynamic motion is associated with disc, facet joint degeneration of cervical spine of $\mathrm{CP}$ patients. Further research is required for cervical dynamic motion changes in $\mathrm{CP}$ patients.

This study has several limitations. First, the number of patients included in this study was limited because of the small number of $\mathrm{CP}$ cases. Second, although the two groups were matched for age and BMI, the height and weight of $\mathrm{CP}$ group was not exactly matched to those of control group. Third, we could not explain the mechanism between cervical morphological changes and involuntary movement in CP patients. Further research, including a closer inspection of the reasons underlying this mechanism, is necessary.

\section{CONCLUSION}

CP patients were more likely to demonstrate progressive morphological degeneration than normal population. Lateral mass morphology in patients with $\mathrm{CP}$ was different from that in normal population. Although longer lateral mass screw could be acceptable in CP patients compared to the normal control, however the selection of the accurate entry point and sagittal angulation is important to avoid facet joint violation during 
the lateral mass screw placement in the CP patient. Sclerotic pedicles and vertebral foramen asymmetry were more frequently identified in CP patients. Pedicle screw placement in a sclerotic pedicle and narrow pedicle could be associated with a higher risk of misplacement. So, preoperative imaging study is critically important to decide the method of posterior instrumentation for the patients with CP.

\section{CONFLICTS OF INTEREST}

The authors have no financial conflicts of interest.

\section{INFORMED CONSENT}

Informed consent was obtained from all individual participants included in this study.

\section{References}

1. Anderson PA, Henley MB, Grady MS, Montesano PX, Winn HR : Posterior cervical arthrodesis with $\mathrm{AO}$ reconstruction plates and bone graft. Spine (Phila Pa 1976) 16(3 Suppl) : S72-S79, 1991

2. Anderson WW, Wise BL, Itabashi HH, Jones $M$ : Cervical spondylosis in patients with athetosis. Neurology 12 : 410-412, 1962

3. Ebraheim NA, Hoeflinger MJ, Salpietro B, Chung SY, Jackson WT : Anatomic considerations in posterior plating of the cervical spine. J Orthop Trauma 5 : 196-199, 1991

4. Furuya T, Yamazaki M, Okawa A, Misawa S, Sakuma T, Takahashi H, et al. : Cervical myelopathy in patients with athetoid cerebral palsy. Spine (Phila Pa 1976) 38 : E151-E157, 2013

5. Harada T, Ebara S, Anwar MM, Okawa A, Kajiura I, Hiroshima K, et al. : The cervical spine in athetoid cerebral palsy. A radiological study of 180 patients. J Bone Joint Surg Br 78 : 613-619, 1996

6. Henry GC : Advances in cerebral palsy. Curr Opin Ortho 13 : 424-431, 2002

7. Hilibrand AS, Carlson GD, Palumbo MA, Jones PK, Bohlman HH : Radiculopathy and myelopathy at segments adjacent to the site of previous anterior cervical arthrodesis. J Bone Joint Surg Am 81 : 519-528, 1999

8. Jeanneret B, Magerl F, Ward EH, Ward JC : Posterior stabilization of the cervical spine with hook plates. Spine (Phila Pa 1976) 16(3 Suppl) : S56-
S63, 1991

9. Kato S, Shoda N, Chikuda H, Seichi A, Takeshita K : Morphological characteristics of cervical spine in patients with athetoid cerebral palsy and the accuracy of pedicle screw placement. Spine (Phila Pa 1976) 39 : E508E513, 2014

10. Kidron D, Steiner I, Melamed E : Late-onset progressive radiculomyelopathy in patients with cervical athetoid-dystonic cerebral palsy. Eur Neurol 27 : 164-166, 1987

11. Kim SW, Limson MA, Kim SB, Arbatin JJ, Chang KY, Park MS, et al. : Comparison of radiographic changes after ACDF versus Bryan disc arthroplasty in single and bi-level cases. Eur Spine J 18 : 218-231, 2009

12. Ko HY, Park-Ko I : Spinal cord injury secondary to cervical disc herniation in ambulatory patients with cerebral palsy. Spinal Cord 36 : 288-292, 1998

13. Lee YJ, Chung DS, Kim JT, Bong HJ, Han YM, Park YS : Surgical treatments for cervical spondylotic myelopathy associated with athetoid cerebral palsy. J Korean Neurosurg Soc 43 : 294-299, 2008

14. Misawa H, Tanaka M, Nakahara S: Therapeutics and a consideration of failed neck surgery in cervical spondylotic myelopathy complicating athetoid cerebral palsy. Spine Spinal Cord 22 : 745-753, 2009

15. Nakashima H, Yukawa Y, Imagama S, Kanemura T, Kamiya M, Yanase M, et al. : Complications of cervical pedicle screw fixation for nontraumatic lesions: a multicenter study of 84 patients. J Neurosurg Spine 16 : 238247, 2012

16. Nazarian SM, Louis RP : Posterior internal fixation with screw plates in traumatic lesions of the cervical spine. Spine (Phila Pa 1976) 16(3 Suppl) : S64-S71, 1991

17. Onari $K$, Kondo S, Mihara $H$, Iwamura $Y$ : Combined anterior-posterior fusion for cervical spondylotic myelopathy in patients with athetoid cerebral palsy. J Neurosurg 97(1 Suppl) : S13-S19, 2002

18. Onibokun A, Khoo LT, Bistazzoni S, Chen NF, Sassi M : Anatomical considerations for cervical pedicle screw insertion: the use of multiplanar computerized tomography measurements in 122 consecutive clinical cases. Spine J 9 : 729-734, 2009

19. Park MS, Lee YB, Moon SH, lee HM, Kim TH, Oh JB, et al. : Facet joint degeneration of the cervical spine: a computed tomographic analysis of 320 patients. Spine (Phila Pa 1976) 39 : E713-E718, 2014

20. Phillips FM, Phillips CS, Wetzel FT, Gelinas C : Occipitocervical neutral position. Possible surgical implications. Spine (Phila Pa 1976) 24 : 775778, 1999

21. Roy-Camille R, Saillant G, Mazel C : Internal fixation of the unstable cervical spine by a posterior osteosynthesis with plates and screws, ed 2. Philadelphia : JB Lippincott, 1989

22. Wong AS, Massicotte EM, Fehlings MG : Surgical treatment of cervical myeloradiculopathy associated with movement disorders: indications, technique, and clinical outcome. J Spinal Disord Tech 18 : S107-S114, 2005 